\title{
Supply Response of Milk Producers to Economic and Non-Economic Factors in Swaziland
}

\author{
Mlungisi C. Sukati \\ Entandweni High School, P. O. Box 6298, Manzini, Swaziland.
}

Micah B. Masuku (Corresponding author),

Department of Agricultural Economics and Management, P. O. Luyengo, Luyengo. M205, University of Swaziland, Swaziland. Tel: 268-7602-6557. E-mail: mbmasuku@ uniswa.sz

Jeremiah I Rugambisa

Department of Agricultural Economics and Management, University of Swaziland, P. O. Luyengo, M2005, Luyengo Swaziland.

Received: August 29, 2017 Accepted: September 13, 2017 Published: October 23, 2017

doi:10.5296/jas.v5i4.11764 URL: https://doi.org/10.5296/jas.v5i4.11764

\begin{abstract}
Supply response indicates the output change due to the change in price and non-price factors. The main aim of this study was to analyse the supply response of milk producers to various economic and non-economic factors. The specific objectives were to determine the responsiveness of milk supply in Swaziland to price and its substitute price (milk powder) and to examine the responsiveness of milk producers to non-economic factors such as rainfall, technology and dairy cattle inventory. The study used time series data from 2010 to 2014 and each year was given in month's in-order to have 60 data points. Several techniques relevant for analysing time series data were employed, which included testing for stationarity of the data, checking if the independent variables if are able to explain the dependent variable (cointegration), running the long-run regression, then dropping some of the residuals which were not significant, after which the Vector Error-Correction Model and the diagnostic tests were conducted. Such analysis included the formal test for stationarity. The Johansen cointegration test was used which provided evidence of cointegration between Milk Output and its determinants. The long-run regression results revealed that Milk Powder Output and
\end{abstract}


Milk Powder Price are significant in determining milk response in the long-run in Swaziland with the elasticities of -0.48 and -0.92 respectively, while the short-run coefficients were- 0.21 and -0.70 respectively. Both variable were significant at $1 \%$ in the short-run and only the Milk Output was significant at 5\% ( $>0.05)$ in the short-run. The Vector Error Correction Model (VECM) came out with the correct -0.129 implying that only $12.9 \%$ of the shocks will be adjusted back to the long-run path within a month. The study therefore, recommended that the Swaziland Government should promote local market share and purpose policies to decrease the country's reliance to imported dairy products, which negatively affects economic development.

Keywords: Cointegration, stationarity, supply response, vector error correction model (VECM).

\section{Introduction}

Agriculture is the largest source of employment for rural households and about $70 \%$ of the population relies on this sector as a means of income in Swaziland. During 2013/2014, agriculture grew by $3.6 \%$ with a GDP share of about $8.6 \%$ (Central Bank of Swaziland (CBS), 2014). Continual drought has significantly declined the output from this sector. Agriculture also has strong linkages with the rest of the economy as a supplier of inputs for manufacturing industries. Furthermore, agriculture has a role in regional development and has the potential to increase economic growth. Agriculture has a pivotal role to play in building a strong economy and in the process, reducing inequalities by increasing incomes and employment opportunities for the poor. The livestock sub-sector accounts for about $14 \%$ of agricultural output and 1\% of total GDP (CBS, 2014). Traditionally this sector is dominated by the production of cattle. Other species reared include poultry, pigs, sheep and goats.

The agricultural sector performed poorly over the years since independence in 1964. The Swaziland Agricultural Development Programme (SADP) (Swaziland Government, 2011) states that in an attempt to improve its performance, agricultural commodity-based markets were well organised in the late 1960s to introduce price incentives and efficient marketing that would encourage farmers to increase production. Basically, it was suggested that farmers would respond to price incentives by increasing output as the central focus of the adjustment reforms in agriculture is to increase agricultural production. Price incentives mean higher returns to farming (farm profits) in the short-run, which will attract more capital both physical and human into agriculture and encourage farmers to adopt new technologies in the long-run. The higher the risk, the higher is the returns. Thus, the efficiency of adjustment in agriculture depends on their short run and long run effects on economic incentives. The extent to which farm decisions respond to economic incentives should be of central concern for policy makers (Lawrence et al., 2007).

Debate on policy responsiveness of agriculture concentrates on the relative importance of price and non-price factors (Binswanger, 1990). Some researchers (World Bank, 1990) attach a fundamental role to price policies, while others (Delgado \& Mellor, 1984; Askari \& Cummings, 1974; McKay, Mosrrissey and Villant., 1997) argue that publicly provided inputs 
are more effective than price in raising output. Others still maintain that prices and the provision of inputs and public support are co-requisites (Schiff \& Montenegro, 1997; Evenson, 1988; Binswanger, 1989).

Swaziland has disparity between the supply and demand of milk. This is due to the fact that milk production is not growing significantly while the population is increasing steadily. According to CBS (2016), the demand for milk has increased by $3.76 \%$ from 57.31 million litres in 2011 to 64.24 in 2015. Domestic production of raw milk increased by $13 \%$ in the year 2013 to 2014. Domestic production continues to fall short of the raising demand for milk in the country, with the imports constituting $85 \%$ of milk in 2015.

The Ministry of Agriculture negotiated a price increase in the purchasing of the raw milk/litre by the processors. The effect of such price increase depends on the open-mindedness of farmers to price incentives. If we believe that increase in the price of milk would inspire farmers to increase production, then response is expected in the 2012/2013 production season (Masuku \& Masuku, 2014). Gosalamang, Belete, Hlongwane et al. (2010) suggested that non-economic factors such as cattle inventory, rainfall and technology have great impact on supply response of dairy production. However, there is no firm evidence so far, which support this hypothesis. Therefore it would be of great interest to establish how responsive milk producers are to various factors. Hence the study will determine the responsiveness of milk producers to shocks by economic and non-economic factors. The study analysed the supply response of milk producers in Swaziland to various economic and non-economic factors. The specific objectives of the study were to;

1) Determine the responsiveness of milk supply in Swaziland to price of milk and its milk powder price (substitute) and

2) Examine the responsiveness of milk producers to non-economic factors such as rainfall, technology and dairy cattle inventory.

\section{Literature Review}

\subsection{Supply Economics}

According to Van Wyk (2011) supply response indicates the output response of change in price and non-price factors. The concept of supply response is sophisticated and different from the supply function that is a static concept (Tripathi, 2008). Supply response is a worldwide concept which indicates the change in quantity supplied with changes in supply movers such as price and non-price factors.

The supply curve of a product such as milk is a blue-print characterising the quantities producers are willing to supply (produce) at a given price, time and locality assuming that all other factors influencing supply, such as technology or production costs, remain the same (ceteris paribus). The slope of the supply curve is figured by the time it takes farmers to adjust to changes. Supply law states that, if the price of a commodity, increase the supply should also increase. Supply response studies are carried out in order to reveal the relationship between inputs and outputs. However, as with any model, specification of the 
model outputs from inputs, limitations and problems exist in the estimation of the model. Typical problems that occur in supply response studies are (Von Bach, 1990); uncertainty in expectations, technological changes and measurement of influence of weather conditions.

Proper model design is vital for supply response analysis. It is of importance that the model should be based on accurate data. The specification of these models provides good support to management in marketing, planning, control and policy. Von Bach (1990) states that supply response studies for agricultural commodities and products can be differentiated into the following:

1. Studies of the supply of individual commodities based on time-series data

2. Studies based on budgeting techniques or linear programming models using typical farms or regions as units of analysis

3. Studies of aggregate supply including both the development of theoretical concepts and estimation of the response of total farm output to changes in product and factor prices.

Most studies of supply response are based on time-series data and either uses the Nerlove (1956) partial adjustment model for single commodities or the method developed by Griliches (1960) for aggregate supply response (Mckay,et al., 1999).

According to Huq and Arshad (2010) supply response is also a tool that is used to evaluate the efficiency of price regimes and enable producers to allocate their resources. Supply response studies are important for taking an account of production policies and incentives. Previous studies in the field of supply response were done in order to understand the price regime. However, except for price, there are various other non-price factors that influence supply which include weather, technology. Supply response studies are also useful for predicting the future for a product within a production environment (Van Wyk, 2011).

\subsection{Agricultural Supply Response}

In developing countries, the agricultural sector is mainly abandoned because economic is thought to have same effect with industrialisation. This anomaly was justified by the belief that industry is a dynamic sector, while agriculture is static and unresponsive to incentives (Gosalamang et al., 2010). This belief has led to the taxing of agriculture by turning domestic marketing against the sector. It is believed that agriculture is insensitive because the resources generated in agriculture could be utilised by other sectors of the economy without significantly affecting agricultural growth (Alemu, et al., 2003).

The task of supply response analysis is the response of local agricultural production to changes in output and input prices, which may be policy induced. The focus may be accumulated agricultural output and its responsiveness to changes in agriculture's terms of where analysis of agricultural growth is the primary objective. On the other hand, the focus may be on individual products to allow analysis of the effects of price movement on commodity composition of agricultural output or to consider certain products of particular quantitative importance on their own right for example milk production. Yields per unit area or animal are of interest as well as the scale of production emulated in areas planted and 
harvested (Hallam, 1990).

A lot of research has been done on estimating the supply response of agriculture with general finding that its response is inelastic (Bond 1983; Chibber, 1989 \& McKay, et al., 1999). However, there has been controversy as to whether aggregate agricultural supply is really not responsive. Schiff and Montenegro (1997) argued that aggregate agricultural supply response to prices is in fact high but that there are other factors such as financing that hinder this response such that a low elasticity is found. Other authors also assert that aggregate agricultural supply is highly responsive but that low elasticities have been observed because of factor prices adjusting in parallel to output prices. A lot of methodological questions have been raised on the previously used models and the estimation techniques applied. These questions range from the reliability of the estimates for predicting supply response to the validity of the estimates. For instance, the major criticism of time series estimates of aggregate agricultural supply response has been that the estimates are drawn for a given price regime hence they mainly reflect short-run variations in prices. Given that agriculture heavily relies on a fixed input (land), it is unlikely that aggregate agricultural supply will respond to short-run fluctuations hence time series estimates are biased downwards (Muchampondwa, 2008).

\subsection{The Conceptual Framework}

The conceptual framework (Figure 1) is a demonstration of the relationships between the variables identified for the study. It shows the relationship between the independent and the dependent variables. For this study, productivity of the milk producers is the dependent variable, while the independent variables are economic factors; which include price of milk, the price of its substitutes for the previous year (milk powder), supply of milk powder, and non-economic factors which include rainfall and technology. These factors, either in isolation or a combination will influence farmers' milk production. The intervening variable is the Swaziland Dairy Board (SDB) that affects milk production and dairy farming at large.

Independent Variables (Economic) Dependent Variable

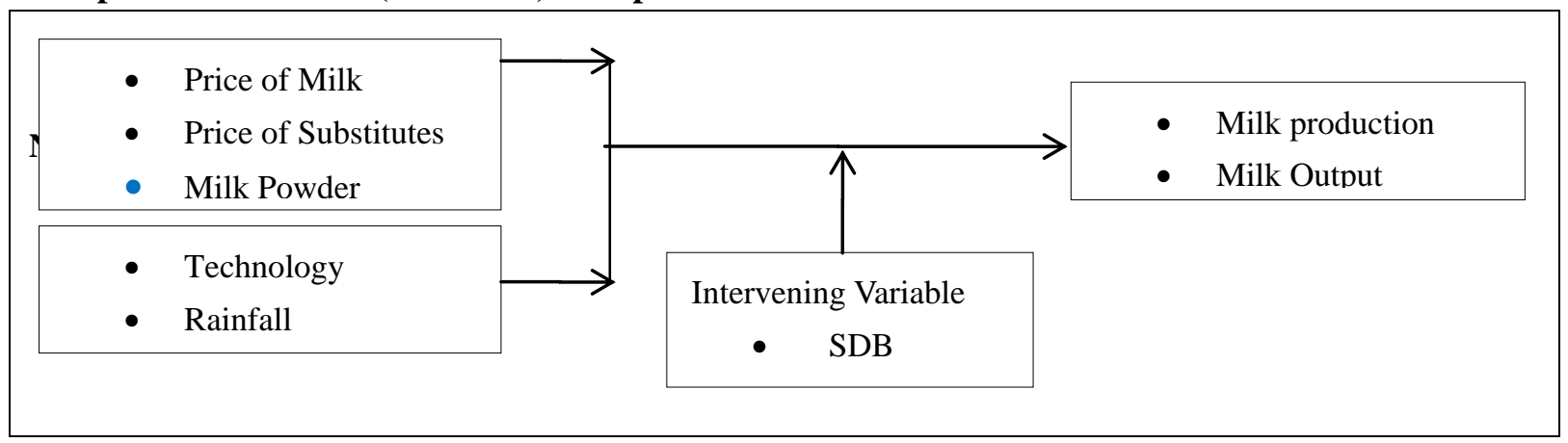

Figure 1. Conceptual framework 


\section{Methodology}

\subsection{Sources of Data}

Historical time series monthly data for the period 2010-2014 were used in the study. The data on domestic producer prices were obtained from Swaziland Dairy Board $(2011 ; 2014)$; the main regulator of milk production and one of the main importers of milk and milk products. Data on monthly precipitation were obtained from the Department of Meteorological Services in the Ministry of Tourism and Environmental Affairs. Data on price of milk powder the main competitors of milk, was extracted from Dairy statistics (2014) maintained by Swaziland Dairy Board. Data on milk powder imports were obtained from the Livestock Department in the Ministry of Agriculture (2014). Data on dairy cattle inventory (population) and annual import (number of dairy cattle imported) was also obtained from the Dairy statistics (2014) by SDB. Data on annual inflation rate as measured by Consumer Price Index (CPI) were obtained from Central Statistics Office (2013) in the Ministry of Economic Planning and Development.

Swaziland is predominantly a dry country; precipitation levels are very low averaging approximately $67 \mathrm{~mm}$ per month in the three years under study. These low rainfall levels adversely affect dairy cattle productivity and render dairy production a very risky endeavour, more so that most farmers rely on natural pastures and surface water. This is because there is continued drought in the region. The drastic decline of cattle numbers in 2012, due to death as a result of hypothermia is clear evidence of the effect of rainfall on cattle production, as rainfall amount was only $310 \mathrm{~mm}$ on the last quarter, suggesting that 2012 was a drought year.

\subsection{Analytical Framework}

The model used for this study was based on the economic assumption to select the variables influencing milk supply and previous work done in this field of the livestock industry. However, it is not always possible to estimate a model suggested by theory, because it may not be possible to include all the variables initiated by theory due to non-availability of data and quantification problems. In practice it is very difficult, for example, to measure agricultural extension services. The supply model for milk supply is based on livestock models used by Von Bach (1999), Abbot et al. (1999) and Ogundeji et al. (2011). However, most of these studies focused on beef supply in the Southern African environment.

Due to the concordance that exist between beef and milk supply, the models used by these research studies were used as a framework for constructing a milk supply model for this study. In order to formulate the long-run and short-run elasticities of supply and to test relationships assumed by theory, the following model was hypothesised for milk production with the variables in their logarithm, as indicated in the equation:

$\log \mathrm{MlkOpt}_{i}=\beta_{0}+\beta_{1} \log M l k O p t_{t-n}+\beta_{2} \log \mathrm{MPr}_{t-n}+\beta_{3} \log _{\mathrm{MPOut}} \mathrm{t}_{t-n}+\beta_{3} \log _{\mathrm{MlkPPr}} \mathrm{r}_{t-n}+$ $\beta_{3} \log R F_{t-n}+e_{t}$ 
Where,

$\operatorname{logMlkOpt} t_{i}$ - the dependent variable of the milk supply model. Milk marketed per month is measured in total local milk output produced by large-scale farmers in litres as a proxy for the total milk output in Swaziland. Milk marketed includes the total number of litres traded through the available marketing channels. This includes milk sold in formal and informal markets and export markets in South Africa. Total local milk production in Swaziland could be used as a dependent variable in the supply model, but due to an incomplete data frequency (only annual data-leading to insufficient number of data points for analysis) on the milk demographics of Swaziland, milk demographics were not considered as a dependent variable in the supply model.

$\log M l k O p t_{t-n}$ - a lag variable of milk marketed is also included as an independent variable in the model leading to general Vector Error-Correction Model (VECM). It can be hypothesised that last month's supply affects this month milk supply due to changes in stock numbers.

$\log M P r_{t-n}$ - the real average monthly producer price (average milk price, $\mathrm{E} / \mathrm{kg}$ across the sole milk processor in Swaziland). This variable is seen as an economic factor influencing supply. As in the law of supply, price plays an important role in product supply. According to Seleka (2001), a positive sign in producer price would imply that milk is viewed as a consumption commodity, and that raises in prices cause producers to sell immediately in response to higher prices. On the other hand, a negative sign would imply that milk is viewed as capital assets in response to rise in current prices, in anticipation of higher future prices leading to the backward-bending supply curve.

The producer price is the average among the milk classification grades. However for the producer price only represents one marketing channel available to producers. Informal prices and Import prices could have been included, as producers react to these indicators. Due to a high correlation between these prices, only one price representative was selected for the supply response model. Furthermore, most of the milk is marketed through the local sole processor. Therefore it is appropriate to include the average producer price offered by the processor in the model.

$\log M P O u t_{t-n}$ - the average monthly Swazi import of Milk Powder (kg), included as an economic factor that functions as a substitute for milk in the dairy market. The milk powder output is hypothesised to influence the milk supply negatively as it acts as a substitute of milk supply. The increase in milk powder supply would have a negative effect on milk supply due to the fact that farmers would decrease their dairy flocks and rather concert to a higher proportion of milk powder importation.

$\log M l k P P r_{t-n}$ - the average monthly Swazi Milk Powder price, included as an economic factor that function as a substitute for milk in the dairy market. The milk powder is included as an economic factor because it affects the supply of milk in the dairy market. It is hypothesised that Milk Powder price would have a negative effect on the milk supply in the dairy market. 
$\log R F_{t-n}$ - the average monthly rainfall, measured in millimetres, across the country and is included as a climatic factor influencing supply. Rainfall is included as a weather variable and is used as an indicator for the condition of Swaziland's natural feed resources. High correlation exists between rainfall and condition of grazing and hence milk production, therefore rainfall can be included as a presentable independent variable representing climate (Von Bach, 1990). As the monthly rainfall increases, the conditions of grazing areas also increase. Therefore rainfall has a positive effect on milk supply.

$e_{t}-$ is the error term in the model

$\beta$ - is the unknown population parameters to be estimated

$\mathrm{t}$ - represents the time period

$\mathrm{n}$ - represents the time lags in the model

Supply in many agricultural commodities reflects the cobweb phenomenon, where supply reacts to price and other factors with a lag of one time or more due to the time it takes for supply decisions to become implemented (Gujarati, 2006). Due to the biological lags between input application and output production, time lags are included in the model. The lags in this study are specified as the maximum to be expected in the light of the technical nature of dairy production.

\section{Results and Discussion}

\subsection{Descriptive Statistics}

Table 1 shows the statistical properties of the data used in the milk supply function. On average 357241.3 litres were produced per month with an average standard deviation of 141 975.5 litres per month. The average milk producer price was E20.72/litre with a standard deviation of E100.49/litre. The average milk powder output was 16480.4 litres $/ \mathrm{kg}$ with a standard deviation of 12752.38 litres. The average milk powder price was E60.18/kg, its deviation from the mean is E17.06/ kg per month. The average monthly rainfall was 71.58 $\mathrm{mm}$ with a standard deviation of $65.78 \mathrm{~mm}$ per month.

Table 1: Statistical Properties of the Original Data

\begin{tabular}{lccccc}
\hline Variable & N & Mean & Std. Dev. & Min & Max \\
\hline Milk Output & 60 & 2388162 & 1909877 & 200036 & 6754132 \\
& & & & & \\
Milk Prices & 60 & 20.72 & 100.49 & 6.25 & 786 \\
Milk Powder Output & 60 & 16480.4 & 12752.38 & 3573.97 & 700003.93
\end{tabular}




$\begin{array}{llllll}\text { Milk Powder Price } & 60 & 60.181 & 17.065 & 34.17 & 96.48 \\ \text { Rainfall } & 60 & 71.58 & 65.78 & 0.1 & 254.7\end{array}$

\subsection{Stationarity/Unit Root Test Results}

The graphical examination of the series is important form of analysis. It allows for the detection of any data capturing errors and inspection of structural disruptions or drifts that may contain unit root tests. It also gives an idea of the stationarity of the data. Figure 1 shows plots of all the variables used in the model in their logarithm form plotted against time.

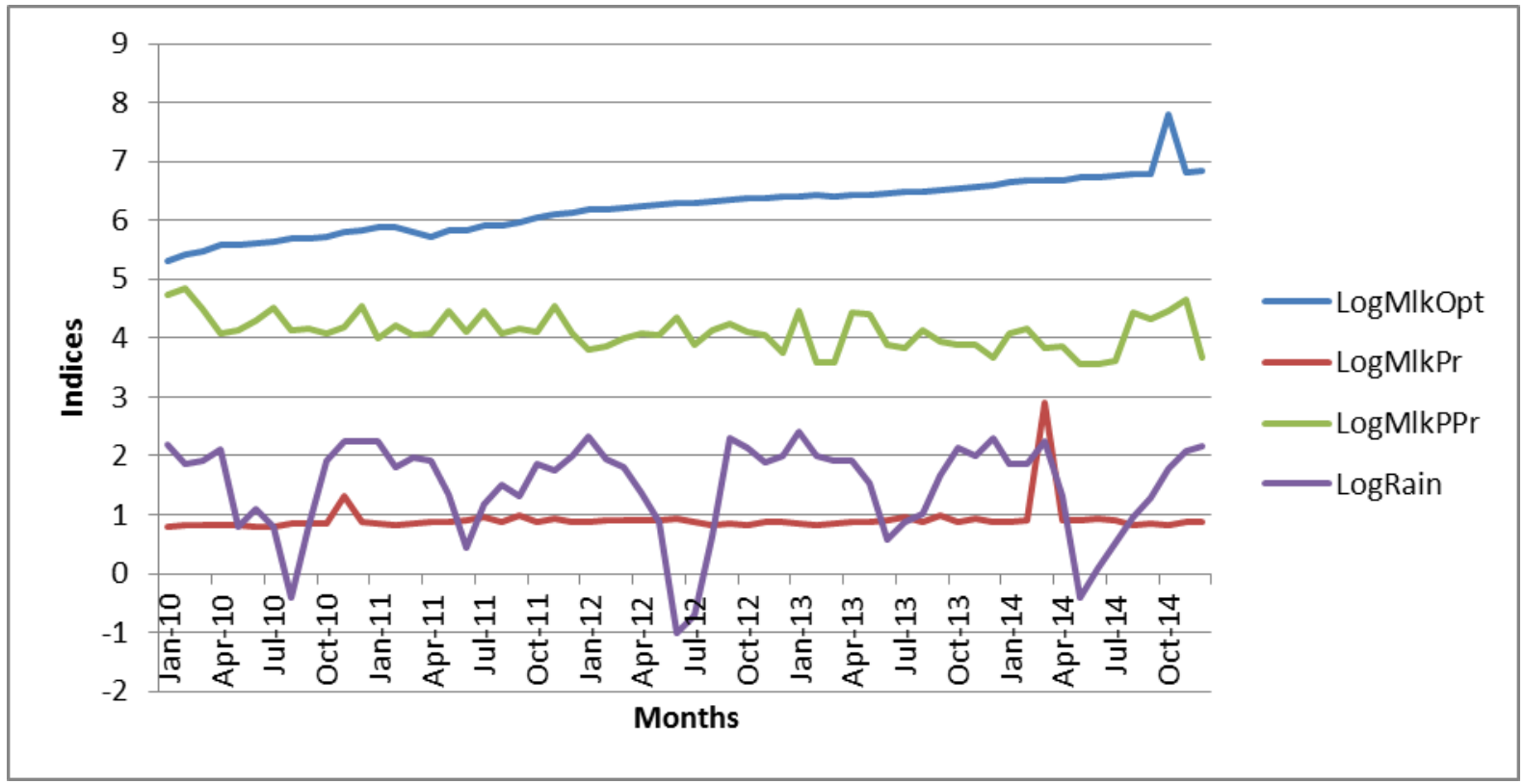

Figure 1: Graphical Presentation of Logarithms of Data

The results presented in Figure 1 indicate that all the variables at level have a time variant mean and variance suggesting that they are not stationary. This is because none of the graphs fluctuate around a zero mean which is an indication of non-stationarity in the variables.

Most time series econometric variables are non-stationary. To achieve a conclusive regression with time series data it is necessary to test for the existence of unit roots (stationarity) in the variables. The first step in the procedure is to test whether the time series data is stationary or not. The study applies the Augmented Dickey-Fuller (ADF) test to detect stationarity and the integration of the variables. A variable is stationary if the ADF statistic is more negative than the Dickey-Fuller critical variables (Gujarati, 2009) as presented in Table 2. In such case the null hypothesis of a unit root is rejected in favour of the alternative hypothesis. The ADF test 
is applied to regressions run in the following forms:

$$
\begin{array}{cc}
\Delta Y_{t}=\psi Y_{t-1}+u_{t} & \text { (without a constant and trend) } \\
\Delta Y_{t}=\beta_{1}+\psi Y_{t-1}+u_{t} & \text { (with a constant) } \\
\Delta Y_{t}=\beta_{1}+\beta_{2} t+\psi Y_{t-1}+u_{t} & \text { (with a constant and trend) }
\end{array}
$$

Where $\mathrm{t}$ is the time trend variable. In each case the null hypothesis is that $\psi=0$, that is, there is a unit root. If the error terms $u_{t}$ are auto-correlated, Dickey and Fuller developed another test, known as the Augmented Dickey-Fuller (ADF) test. This test is conducted by augmenting all the three forms of equations by adding the lagged values of the dependent variable $\Delta Y_{t}$. This means that equation (3) is then modified such as the ADF test for stationarity is based on the following equation:

$$
\Delta Y_{t}=\beta_{1}+\beta_{2} t+\psi Y_{t-1}+\sum \alpha_{i} \Delta Y_{t-1}+u_{t}
$$

Where $Y_{t}$ is the series tested for stationarity, $\beta_{1}, \beta_{2}, \psi$ are parameters and $u_{t}$ is white noise. The number of lagged difference terms of $\Delta Y_{t}$ is meant to remove any dynamic structure present in the dependent variable, to ensure that $u_{t}$ is not auto-correlated and is white noise.

Table 3 presents the ADF unit root results and indicate that all the variables are non-stationary at levels. At level determine the current time. The results were carried out with no constant and trend, with constant but no trend and with trend and constant.

Table 2: Augmented Dickey-Fuller (ADF) unit root results at levels

\begin{tabular}{llll}
\hline Variable & Constant & Constant, tread & None \\
\hline Log (MlkOpt) & $-2.028(-2.89)$ & $-7.385(-3.45)$ & $-0.892(-1.95)$ \\
Log (MlkPr) & $-7.550(-2.89)$ & $-7.684(-3.45)$ & $-1.521(-1.95)$ \\
Log (MlkPOpt) & $-5.601(-2.89)$ & $-6.221(-3.45)$ & $-0.723(-1.95)$ \\
& & & \\
Log (MlkPPr) & $-4.121(-2.89)$ & $-4.525(-3.45)$ & $-0.367(-1.95)$ \\
Log (Rain) & $-3.396(-2.98)$ & $-3.339(-3.45)$ & $-1.527(-1.95)$
\end{tabular}

Numbers in brackets are Dickey-Fuller critical values at 5\% significant level

The null hypothesis for each variable is stated as:

Ho: Series contains a unit root 
H1: Series is stationary

As the results presented in Table 4.3 indicate, all the variables are non-stationary at levels. This is because the ADF test statistic is less negative compared to the Dickey-Fuller critical values in all the variables. We fail to reject the null hypothesis which means the series contain a unit root. A summary of the Dickey-Fuller critical values are presented in Table 3

The null hypothesis of a unit root is not rejected for all variables at $5 \%$ levels of significance. This implies that all the variables included in the specified model are stochastic at least at $5 \%$ significance level.

Table 3: Critical Dickey-Fuller values

\begin{tabular}{|c|c|c|c|c|c|c|}
\hline & \multicolumn{2}{|c|}{ Constant } & \multicolumn{2}{|c|}{ Constant, trend } & \multicolumn{2}{|l|}{ None } \\
\hline Sample size & $1 \%$ & $5 \%$ & $1 \%$ & $5 \%$ & $1 \%$ & $5 \%$ \\
\hline 25 & -3.75 & -3.00 & -4.38 & -3.60 & -2.66 & -1.95 \\
\hline 50 & -3.58 & -2.93 & -4.15 & -3.50 & -2.62 & -1.95 \\
\hline 100 & -3.51 & -2.89 & -4.04 & -3.45 & -2.60 & -1.95 \\
\hline 250 & -3.46 & -2.88 & -3.99 & -3.43 & -2.58 & -1.95 \\
\hline 500 & -3.44 & -2.87 & -3.98 & -3.42 & -2.58 & -1.95 \\
\hline$\infty$ & -3.43 & -2.86 & -3.96 & -3.41 & -2.58 & -1.95 \\
\hline
\end{tabular}

$1 \%$ and $5 \%$ Critical values

The next step is for the stationarity of the variables taking their first differences. Again this involves testing the following hypothesis:

Ho: Series contains a unit root

$\mathrm{H} 1$ : Series is stationary

The results of the ADF test are presented in Table 5 and they indicate that all the variables are stationary at their first order difference. This is because the ADF test statistic is more negative than the Dickey-Fuller critical values for all the variables. In all the variables the null hypothesis of non-stationarity is rejected at 
least at 5\% significance level at constant and trend, while DLog(MlkOpt), DLog( MlkPr), DLog( MlkPOpt), DLog (MlkPPr) and DLog (Rain) are significant at $1 \%$. The result suggests that all the variables are cointegrated of the order one I(1) and they move closely together overtime. Therefore, the long-run regression on the levels of the specified variables is not spurious.

Table 4: Augmented Dickey Fuller (ADF) results at first difference

\begin{tabular}{|c|c|c|c|}
\hline Variable & Constant & Constant, tread & None \\
\hline Log (MlkOpt) & $-2.03 * *(-2.89)$ & $-7.38(-3.45)$ & $-0.89 * *(-1.95)$ \\
\hline $\log (\mathrm{MlkPr})$ & $-7.55(-2.89)$ & $-7.68(-3.45)$ & $-1.52 *(-1.95)$ \\
\hline Log (MlkPOpt) & $-5.60 \quad(-2.89)$ & $-6.22(-3.45)$ & $-0.72 * *(-1.95)$ \\
\hline Log (MlkPPr) & $-4.12(-2.89)$ & $-4.53(-3.45)$ & $-0.37 * *(-1.95)$ \\
\hline Log (Rain) & $-3.40 \quad(-2.89)$ & $-3.34(-3.45)$ & $-1.53 *(-1.95)$ \\
\hline
\end{tabular}

Numbers in brackets are Dickey-Fuller values at 5\% significance level; $*$, ** indicate significance at 5\% and $1 \%$ 


\subsection{Cointegration and Error Correction Model}

The variables became stationary after differencing once. They are said to be integrated of order one, denoted by I (I). Some variables will become stationary after differencing twice and they are said to be integrated of order two, denoted by I (2). The study applies the Engle \& Granger (1987) residual-based method for this analysis. The Engle \& Granger definition of co-integration states that if two (more series are linked to form an equilibrium relation spanning the long-run, then even though the series themselves contain stochastic trend (non-stationary) they will nevertheless move closely together in the long-run and the difference between them will be stable. In general, if $Y_{t}$ is $\mathrm{I}(\mathrm{d})$ and also $\mathrm{I}(\mathrm{d})$, where $\mathrm{d}$ is the same value, these two series can be co-integrated. If is that the case, the regression on the levels of the two variables is meaningful and not spurious. Cointegration necessitates that the variables be integrated of the same order. Thus the first step in cointegration analysis is to test each variable to determine its order of cointegration. This has been done in the previous section where the ADF test has been used to detect the number of unit roots in each of the variables. There are three cases that can determine if the study needs to proceed to cointegration analysis or not:

i. If all the variables are stationary $(\mathrm{I}(0))$, it is not necessary to proceed since the standard time series methods apply to stationary variables. In other words, we can go straight to apply the classical regression analysis.

ii. If the variables are integrated of different order, it is possible to conclude that they are not cointegrated.

iii. If the variables are integrated of the same order then we proceed with cointegration analysis.

Since the study has already established that the variables in the model are integrated of same order, then the next step is to estimate the long-run equilibrium relationship of equation (5):

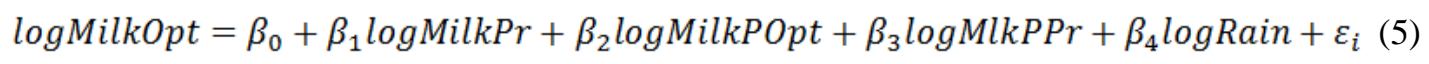

The obtained residuals of the equation are then tested for unit root using the ADF test. The test is said to be single equation-approach and it entails determining whether the residuals from the regression are stationary at levels. The results of the long-run equation are presented in Table 5.

Table 5: Long-run regression results

\begin{tabular}{lllll}
\hline Variable & Coefficient & Standard error & t-statistic & p-value \\
\hline Constant & 9.693779 & 0.9411491 & 10.30 & 0.000
\end{tabular}




$\begin{array}{lllll}\log (\mathrm{MlkPr}) & 0.0815832 & 0.205248 & 0.40 & 0.693 \\ \text { LogMlkPOpt } & -0.4836086 & 0.1822395 & -2.65 & 0.010^{*} \\ \text { LogMlkPPr } & -0.9214409 & 0.3280774 & -2.81 & 0.007^{* *} \\ \text { LogRain } & 0.0246001 & 0.0687501 & 0.36 & 0.722\end{array}$

R-square $=0.2467$

Adjusted R-Square $=0.1919$

F-statistic $=4.50$

Prob $($ F-statistic $)=0.0032$

$* *$ indicate significance at $5 \%$ and $*$ significance at $1 \%$

The long-run regression results presented in Table 5 reveals that the coefficients of Milk Powder Output and Milk powder price are significant in local milk production performance in the long-run with elasticities -0.48 and -0.92 respectively. All these variables were found to be significant at $10 \%$ level of significance. In this case, a percentage increase in milk powder output will cause a $48 \%$ decrease in the milk output in the long-run. The p-value for Milk Powder output is 0.010 , which shows statistical significance at $10 \%$ level. Hence, we conclude that in the long-run an increase in Milk Powder Output will lead to degrading the milk production. The results are consistent with the findings by Van Wyk (2011).

The coefficient for the milk powder price is -0.92 with a p-value of 0.007 . This shows significance at $1 \%$ level. The coefficient indicates that when that a one percent increase in Milk Powder price will cause a decrease in Milk Output by $92 \%$. This shows a high level of inelasticity of the milk production in the long-run for the period January 2010- December 2014. These results support the findings of Halvorson (1958) whose study confirmed that United States milk substitutes are elastic with respect to milk price.

The milk price coefficient shows that there is a positive relationship between this variable and milk output. This result confirms the expectation that the milk price increase will make out milk production more competitive in the local market. So an increase in the milk price denotes an increase in milk output, hence the positive relationship. The coefficient of 0.08 means that a percentage point in inflation will lead to milk output increasing by $8 \%$ in the long-run, ceteris peribus.

Although the effect of rainfall is positive, it shows a very low effect on the long-run. These 
results are consistent with the weather patterns in Swaziland because dairy production is largely depended on fodder availability hence rainfall.

\subsection{Cointegration}

Once it has been established that the variables are integrated of the same order, the next step is to determine whether there is a long-run equilibrium relationship amongst them Cointegration describes the presence of an equilibrium or stationarity among two or more times series if each of which is individually non-stationary. The advantage of cointegration approach is that it allows one to integrate the long-run and short-run relationship between variables within an integrated framework. As mentioned earlier the study uses the Johansen approach of cointegration analysis. This approach generates ratio tests, namely the Trace and the Maximum Eigen value statistic test, which are mainly used to determine the number of cointegrated equations given by the cointegration rank $r$. the Trace statistic tests the null hypothesis of $\mathrm{r}$ cointegration relations against the alternative of $\mathrm{k}$, cointegration relations, where $\mathrm{k}$ is the number of endogenous variables for $\mathrm{r}=0,1, \mathrm{k}-1$. The Maximum Eigen Value statistic tests the null hypothesis of $\mathrm{r}$ cointegrating vectors against the alternative of $\mathrm{r}+1$ cointegrating vectors (Tripathi, 2008). The results of the Johansen test are shown in Table 6.

Table 6: Johansen test results
Maximum Rank
Parms
LL
Eigen Value
t-statistic
$5 \%$ Critical

\begin{tabular}{llllll}
\hline 0 & 30 & -33.863558 &. & 119.328 & 68.52 \\
1 & 39 & 13.50777 & 0.55215 & 72.737 & 47.21 \\
2 & 46 & 3.57900 & 0.44523 & 38.564 & 29.68 \\
3 & & & & & \\
4 & 51 & 13.2494 & 0.24821 & 19.223 & 15.41 \\
5 & 54 & 21.5231 & 0.24821 & $2.676^{*}$ & 3.76 \\
& 55 & 22.86095 & 0.04509 & &
\end{tabular}

Table 6 presents test statistics and their critical values of the null hypothesis of no cointegration in line one and one or fewer cointegrating equations in line two. Based on the results, we reject the first three ranks but in rank three the t-statistic (2.676) is less than 5\% critical value (3.76). So we are able to reject the null hypothesis of no integration. It shows that at least three equations move closely together in the long-run. We can now run the Error-Correction model. 


\subsection{Diagnostic Test Results}

\subsubsection{Testing for Serial Correlation}

Serial correlation is a statistical term used to describe the situation when the residual is correlated with lagged values of itself. In other words, if the residuals are correlated, we sometimes call this situation autocorrelation. Serial correlation can occur due to incorrect model specification for example omitted variables; use of incorrect functional form, and incorrectly transformed data. To test for autocorrelation in the residual, the study used the Breusch-Godfrey (BG) serial correlation LM test. When using the BG test, the null hypothesis is that there is no serial correlation in the residuals. The decision is such that if the p-value of Obs*R-squared is less than $5 \%(0.05)$ we reject the null hypothesis that there is no serial correlation (no correlation between residuals) against the alternative hypothesis that there is serial correlation in the residuals. The results of the BG test are presented in Table 7

Table 7 Breusch-Godfrey (BG) LM for auto-correlation test results

$\begin{array}{llll}\text { Lags (p) } & \text { Chi }^{2} & \text { Df } & \text { Pro }>\mathrm{Chi}^{2} \\ 1 & 38.348 & 1 & 0.0000\end{array}$

The results from Table 7 shows that the $\mathrm{Chi}^{2}$ (38.348) is greater that the Probability of the $\mathrm{Chi}^{2}$; hence we reject the null hypothesis, meaning that there is serial correlation between the residuals. To correct the situation, the second lag of the output was used. The test was redone after the remedy and the results are shown in Table 8.

Table 8 Breusch-Godfrey (BG) LM for corrected auto-correlation test results

$\begin{array}{llll}\text { Lags (p) } & \text { Chi }^{2} & \text { Df } & \text { Pro }>\mathrm{Chi}^{2} \\ 2 & 0.249 & 1 & 0.6176\end{array}$

Ho: no serial correlation

Now the $\mathrm{Chi}^{2}$ value $(0.249)$ is less than the $\mathrm{Pro}>\mathrm{Chi}^{2}$ (0.6176), we fail to reject the null hypothesis, meaning there is no serial correlation between the residuals.

\subsubsection{Testing for Normality}

One of the main assumptions of the classical normal linear regression model is that the residuals that are normally distributed. The hypothesis tests on the coefficients obtained by OLS are based on this assumption. To detect weather the residuals are normally distributed or not the study used the Jarque-Bera Statistic. The null hypothesis is that the residuals are normally distributed against the alternative that the residuals are not normally distributed. 


\section{Macrothink}

Journal of Agricultural Studies

ISSN 2166-0379

2017, Vol. 5, No. 4

Again if the p-value of Jarque-Bera statistics is less than 5\% (0.05) we reject null hypothesis that the residuals are normally distributed and accept the alternative, that is, residuals are not normally distributed. The results of this test are shown in Table 9.

Table 9 Normality test (Jarque-Bera)

Jarque-Bera $\quad 0.25795$

Probability $\quad 0.164968$

One of the diagnostic test proved that there is economic problem in the milk supply model but it was corrected and the model was specified. This is now confirmed by the results of the diagnostic test and Breusch-Godfrey (BG) LM test suggest that no problem of serial correlation is now found. The Jarque-Bera test does not reject the presence of normality of errors.

\subsection{Error-Correction Model (ECM)}

If the variables in the study are cointegrated, the residuals from the equilibrium regression can be used to estimate the error correction model. This also helps to analyse the long-run and short-run effects of the milk supply model as well as to see the adjustment coefficient, which is the coefficient of the lagged residual terms of the long-run relationship among the variables. This technique has an advantage as it gives the speed of adjustment parameter, which indicates how quickly the system returns to equilibrium, after a random shock. The initial error correction model for milk supply model was presented using ordinary least square (OLS) as follows:

$$
\text { DlogMlkOpt }=\beta_{0}+\beta_{1} \text { DlogMlkPOpt } t_{-1}+\beta_{2} \log M l k P P r_{-1}+\beta_{4} E C M_{-1}+\varepsilon_{t}
$$

Equation (6) was specified by lagging the Milk Output in order to achieve a robust and parsimonious milk supply and the results are shown in Table 10. 
Table 10 Final Short-run regression results (ECM)

\begin{tabular}{lllll}
\hline Variable & Coefficient & Standard-error & t-statistic & p-value \\
\hline Constant & 0.370105 & 0.0235228 & 1.57 & 0.116 \\
DLog(MlkOpt $)$ & 0.3541561 & 0.1156061 & 3.06 & $0.002^{*}$ \\
DLog(MlkPOpt $)_{-1}$ & -0.211144 & 0.0851177 & -2.48 & $0.013^{*}$ \\
DLog(MlkPPr $)_{-1}$ & -0.702066 & 0.1190976 & -0.59 & 0.556 \\
ECM & & & & \\
R-square $=0.79$ & -0.12858 & 0.228355 & -0.563 & $0.000^{*}$ \\
Adjusted R-Square $=0.535$ & & & \\
Prob $($ F-statistic $)=0.0000014$ & & & \\
\hline
\end{tabular}

*indicate significance at $5 \%$

The value of the coefficient of determination (adjusted $\mathrm{R}^{2}$ ), of 0.54 means that about $54 \%$ variation in milk output is explained by included variables in the short-run. This shows that this is the perfect supply model for milk supply response. However, before making any inferences out of the regression results, it is important to run a number of diagnostic tests to determine where any of the ordinary least squares (OLS) assumptions have been violated. If any of the assumptions are violated, then remedial measures must be taken before any inferences are made. The milk supply model was tested for normality, serial correlation and linearity. All the diagnostic tests support the statistical appropriateness of the milk supply equation. Diagnostic tests performed indicated that the residuals are normally distributed, serially correlated but corrected by lagging the log of the output twice, serially uncorrelated and that the model is correctly specified. 


\section{Conclusions and Recommendations}

\subsection{Conclusion}

The long-run regression results revealed that milk powder output and milk powder price were significant in determining the milk supply response in the long-run with elasticities of -0.58 and -0.92 respectively, while the short-run coefficients were -0.211 and -0.702 respectively. All these variables were found to be significant at $1 \%$ level of significance in the long-run and significant at $5 \%$ in the short-run. The Milk Price and Rainfall results were consistent with the findings by Halvorson (1955) whose study confirmed that if monthly time periods are considered, analysis suggest some assumptions are questionable.

The error-correction mechanism $\left(\mathrm{ECM}_{-1}\right)$ was found to be significant at $5 \%$ and had a negative coefficient of -0.129 suggesting that any short-run deviation of milk output adjust very slowly to its determinants with a lag and that is about $12.9 \%$ of the discrepancy between the long-run and short-run milk supply with a month. This shows a very slow adjustment towards the equilibrium. This was in line with expectation of the ECM which is supposed to be negative and less than one.

\subsection{Recommendations}

The findings of the study show that milk producers respond very slow to the long-run (desired output). The Ministry of Agriculture through the Swaziland Dairy Board needs to improve the efficiency of the milk producers through provision of production inputs subsidies, improve the extension service. SDB need to also improve the pricing regime in order to improve the supply response because producer end up selling their products informally.

\section{References}

Abou-Talb, A. E., \& El Begawy, M. A. (2008). Supply Response for Some Crops in Egypt: A Vector Error Correction Approach. Journal of Applied Sciences Research, 12, (4) 1647-1657.

Alemu, Z. G., Oosthuizen, K., \& Van Schalkwyk H. D. (2003) Grain response in Ethiopia: An error correction approach. Agrekon. 42, (5): 389-403.

https://doi.org/10.1080/03031853.2003.9523631

Banerjee, A, Dolado, J. Hendry, D. \& Smith, G. (1986). Exploring equilibrium relationships in econometrics though static models: Some Carlo evidence. Oxford Bulletin of Economics and Statistics. 48(3): 253-276. https://doi.org/10.1111/j.1468-0084.1986.mp48003005.x

Binswanger, H.P. (1974). A cost function approach to the measurement of elasticities of factor demand and elasticities of substitution; American Journal of Agricultural Economics, 56 (8), 377-386. https://doi.org/10.2307/1238771

Brooks, C. (2002). Introductory Econometrics for Finance. Cambridge University.

Bulut, Z. B. (2009). Demand and Supply of Real Estate Market in Turkey: A Cointegration Analysis. Master's Thesis. Department of Bilkent University.

Central Bank of Swaziland. (2005). Annual report April 2004-March 2005. Central Bank of 
Swaziland, Mbabane.

Central Bank of Swaziland. (2016). Annual report April 2015-March 2016. Central Bank of Swaziland, Mbabane.

Colman, D. (1983). A Review of the Arts of Supply Response Analysis. Review of Marketing and Agricultural Economics, 51, ( 3), 201-230.

Dickey, D.A. \& Fuller, W.A. (1979). Distribution of the Estimation for Autoregressive Time Series with a Unit Root. Journal of American Statistical Association, 79: 355-367.

https://doi.org/10.1080/01621459.1984.10478057

Engle, R., \& Granger, C. W. J. (1987). Cointegration and Error-correction: Representation, Estimating and Testing. Econometrica, 55(2): 251-276. https://doi.org/10.2307/1913236

Gosalamang D.S., Betele A., Hlongwane J.J. \& Masuku M.B. (2010). Econometric analysis of supply response among beef farmers in Botswana, pdf; African Journal of Agricultural Research, 7, (31), 4383-4389.

Guarda, P. (1996). A consumption function for Luxembourg: Estimating an error-correction model. Mod-L2 Project Report [Online], 29. http://www.crpcu.lu/projects/modl.html.

Griliches, Z. (1960). Z. (1960). Estimates of the Aggregate U.S. Farm Supply Function. Agricultural \& Applied Economics Association, 42, (2), 282-293.

Gujarati, D. N. (1995). Basic Econometrics. McGraw Hill: New York.

Gujarati, D. N. (2009). Basic Econometrics. McGraw Hill: New York.

Granger, C. W. \& Newbold, P. (1974). Spurious Regressions in Econometrics. Journal of Econometrics 2:111-120 https://doi.org/10.1016/0304-4076(74)90034-7

Hallam, D. (1990). Econometric Modelling of Agricultural Commodity Markets. Routledge, 11 new Fatter Lane: London.

Hwang, J. (2002). The demand for money in Korea: Evidence from the cointegration test. Int'l advances in Econs. Res. 8(3): 188-195.

Huq, A.S.M.A. \& Arshad, F.M. (2010). Supply Response of Potato in Bangladesh: Vector Error Correction Approach. Journal of Applied Sciences, 10, (11), 895-902

Lawrence, D. M, Oleson, K. W, Flanner, M. G, Thornton, P. E \& Swensin, S. C. (2007). Parameterization Improvements and Structural Advances in Version 4 of the Community Land Model. Journal of Advances in Modelling Earth Systems. (3): 15-27

McKay, A., Mosrrissey, O., \& C. H. Vaillant. (1999). Aggregate Agricultural Supply Response in Tanzania. Journal for International Trade and Economic Development. 8(1): 107-123. https://doi.org/10.1080/09638199900000008

Muchampondwa, E. (2008). Estimation of the aggregate agricultural supply response in Zimbabwe: The ARDL approach in cointegration Working Paper Number 90: University of 
Cape Town.

Nerlove, M. (1956). Estimates of the Elasticities of Supply of Selected Agricultural Commodities. Journal of Farm Economics, 38, (2): 496-509. https://doi.org/10.2307/1234389

Nerlove M. (1958). Distributed Lags and Estimation of Long-run Supply and Demand Elasticities: Theoretical Considerations. Agricultural \& Applied Economics Association, 40, (2): 301-311. https://doi.org/10.2307/1234920

Schiff, M., \& Montenegro, C. E. (1997). Aggregate Agricultural Supply Response in Developing Countries: A Survey of Selected Issues. Economic Development and Cultural Change 45(2): 393-410. https://doi.org/10.1086/452279

Skosana, V. S., Kabuya \& Rugambisa, I. J. (2013). Determinants of Exports in Swaziland: An Empirical Analysis form 1980 to 2010. Master's thesis; University of Swaziland.

Stock, J. H. \& Watson, M. W. (1993). A Simple Estimator of Cointegration Vectors in Higher Order Integrated Systems: Econometrica 61 (4): 783-820. https://doi.org/10.2307/2951763

Townsend, R. F. (1997). Econometric Methodology: The Role of Theory and Observation in Agricultural Economics Research. Agrekon, 36, (3), 325-347.

https://doi.org/10.1080/03031853.1997.9523468

Tripathi, A. (2008). Estimation of Agricultural Supply Response by Co-integration Approach. Research Report, Indira Gandhi Institute of Development Research, Mumbai.

Van-Wyk, D. N. (2011). A Quantitative Analysis of Supply Response in The Namibian Mutton Industry. MSc Thesis, Faculty of Engineering at Stellenbosch. University, South Africa. https://doi.org/10.7166/23-1-231

Von Bach, H.J.S. (1990). Supply Response in Namibian Beef Industry. MSc Thesis, Department of Agricultural Economics, University of Pretoria, Pretoria.

World Bank .(2013). World population estimates; World Bank.

Yule, U. (1926). Why Do We Sometimes Get Nonsense-Correlation Between Time Series? A Study in Sampling and the Nature of Time Series. Journal of the Royal Statistical Society 89: 1-63. https://doi.org/10.2307/2341482

\section{Copyright Disclaimer}

Copyright for this article is retained by the author(s), with first publication rights granted to the journal.

This is an open-access article distributed under the terms and conditions of the Creative Commons Attribution license (http://creativecommons.org/licenses/by/4.0/). 